\title{
BMJ Global Health Childhood morbidity and its determinants: evidence from 31 countries in sub-Saharan Africa
}

\author{
Sulaimon T Adedokun, ${ }^{1}$ Sanni Yaya (1) ${ }^{2,3}$
}

To cite: Adedokun ST, Yaya S. Childhood morbidity and its determinants: evidence from 31 countries in sub-Saharan Africa. BMJ Global Health 2020;5:e003109. doi:10.1136/ bmjgh-2020-003109

Handling editor Seye Abimbola

Received 8 June 2020

Revised 2 August 2020

Accepted 20 August 2020

Check for updates

(c) Author(s) (or their employer(s)) 2020. Re-use permitted under CC BY-NC. No commercial re-use. See rights and permissions. Published by BMJ.

${ }^{1}$ Department of Demography and Social Statistics, Obafemi Awolowo University, Ile-Ife, Osun, Nigeria

${ }^{2}$ School of International Development and Global Studies, University of Ottawa, Ottawa, Ontario, Canada

${ }^{3}$ The George Institute for Global Health, Imperial College London, London, United Kingdom

Correspondence to

Dr Sanni Yaya;

sanni.yaya@uottawa.ca

\section{ABSTRACT}

Background Although under-five mortality reduced globally from 93 per 1000 live births in 1990 to 39 in 2018, sub-Saharan Africa witnessed an increase from $31 \%$ in 1990 to $54 \%$ in 2018. Morbidity has been reported to contribute largely to these deaths. This study examined the factors that are associated with childhood morbidity in sub-Saharan Africa.

Methods Demographic and Health Surveys of 31 countries in sub-Saharan Africa were used in this study. The study involved 189069 children who had or did not have fever, cough or diarrhoea in the 2 weeks preceding the surveys. Descriptive statistics and binary logistic regression were applied in the analysis.

Results About $22 \%$ of the children suffered from fever, $23 \%$ suffered from cough and $16 \%$ suffered from diarrhoea. While the odds of experiencing fever increased by $37 \%$ and $18 \%$, respectively, for children from poorest and poorer households, children of women aged 15-24 and $25-34$ years are $47 \%$ and $23 \%$, respectively, more likely to experience diarrhoea. The probability of suffering from morbidity increased for children who are 12-23 months, of higher order birth, small in size at birth and from households with non-improved toilet facility. Conclusions This study has shown that childhood morbidity remains a major health challenge in subSaharan Africa with socioeconomic, maternal, child's and environmental factors playing significant roles. Efforts at addressing this problem should consider these factors.

\section{BACKGROUND}

Although under-five mortality has reduced globally from 93 per 1000 live births in 1990 to 39 in 2018, sub-Saharan Africa is still grappling with high under-five mortality. ${ }^{1}$ While sub-Saharan Africa and Central and Southern Asia are responsible for more than $80 \%$ of the 5.3 million under-five deaths in 2018, three out of the five countries where half of the global under-five deaths occurred are located in sub-Saharan Africa. ${ }^{1}$ This made the region to witness an increase in underfive mortality from $31 \%$ in 1990 to $54 \%$ in 2018. ${ }^{2}$ Records also show that the leading causes of such deaths include preterm birth complications (18\%), pneumonia $(15 \%)$,

\section{Key questions}

What is already known?

- Childhood morbidity has contributed substantially to under-five mortality in sub-Saharan Africa.

- Policymakers expect a considerable reduction in childhood morbidity as a result of huge resources committed to prevention and control of morbidity among children.

What are the new findings?

- Prevalence of childhood morbidity increases with decreasing household wealth.

- Children of non-working women are less likely to suffer from morbidity compared with children of working women.

- Size of child at birth is significantly associated with childhood morbidity.

What do the new findings imply?

- Improving child health requires policies that will focus on household poverty alleviation, communitybased health education programmes for women and comprehensive free healthcare for under-five children.

intrapartum-related events (13\%), congenital abnormalities (9\%), diarrhoea (8\%), neonatal sepsis $(7 \%)$ and malaria $(5 \%){ }^{2}$

In an attempt to reduce the effects of morbidity on under-five mortality, different initiatives have been introduced. One of these is the Integrated Global Action Plan for the Prevention and Control of Pneumonia and Diarrhoea. This Plan highlights three key intervention areas: protection, prevention and treatment. ${ }^{3}$ While protective intervention focuses on exclusive breast feeding, adequate complementary feeding and continued breast feeding and vitamin A supplementation, preventive intervention emphasises immunisation and safe drinking water, sanitation and hygiene. ${ }^{3}$ Treatment intervention involves oral rehydration salts and zinc supplements. ${ }^{3}$ Substantial investments have also been made on initiatives aimed at combating malaria. 
The global funding for malaria control and elimination in 2017 was $\$ 3.1$ billion. ${ }^{4}$ In this respect, a package of interventions incorporating prevention and treatment of malaria in children was launched. This package involves (1) use of long-lasting insecticidal nets, (2) seasonal malaria chemoprevention for children aged 3-59 months in areas with highly seasonal transmission of the Sahel subregion of Africa, (3) intermittent preventive therapy for infants in areas of moderate to high transmission in sub-Saharan Africa, and (4) prompt diagnosis and effective treatment of malaria infections. ${ }^{5}$

Despite the huge investments on these initiatives, childhood morbidity remains a major health challenge in sub-Saharan Africa. Some of the factors identified as influencing morbidity among children include maternal education, maternal age, child's nutritional status, child's age, household wealth, residence, handwashing, sanitation, water source, use of insecticide-treated nets and exposure to information on morbidity, among others. ${ }^{6-17}$ For instance, some studies showed that diarrhoea infection is higher among children whose mothers have no education and do not wash their hands after using the toilet. Other studies revealed that malaria and acute respiratory infection are higher among children in rural setting and children whose mothers are 16-17 and 28-33 years of age. Most of these studies considered childhood morbidity at country level. There is a need for a study that would examine the factors influencing childhood morbidity at subregional level. This study aimed at filling this gap by pooling data from 31 countries together in order to apply a wholistic approach to the study of childhood morbidity in sub-Saharan Africa. This approach will provide a robust information that would contribute to a better understanding of the phenomenon.

\section{METHODS}

\section{Study design}

Data from Demographic and Health Surveys of 31 subSaharan African countries were used in the study. The surveys, which are conducted at intervals of 5 years in every country, are cross-sectional and provide information on health and population characteristics. The data sets were from surveys conducted between 2010 and 2018 in the countries under consideration.

\section{Sampling technique}

The sample was selected for the surveys using multistage sampling technique. Each country was divided into clusters or communities. From each cluster, urban and rural areas were selected. Households were thereafter selected from the chosen urban and rural areas. Women within the reproductive age of 15-49 years in each household were eligible for interview. Information about the children was obtained from the mothers of such children.

\section{Data collection}

The use of questionnaire was adopted as a means of information gathering in the surveys. Questionnaires were administered by interviewers who engaged respondents in a face-to-face interview. Information obtained from each respondent related to sociodemographic characteristics, reproductive issues, breast feeding, immunisation, childhood diseases, delivery and postnatal care, and health services use for children, among others.

\section{Outcome variable}

Three outcome variables were used in the study which involved children under the age of 5 in sub-Saharan Africa. The outcome variables include fever, cough and diarrhoea. Children who suffered from each of these diseases were categorised as 'Yes' while those who did not suffer from any of the diseases were categorised as 'No'.

\section{Independent variables}

The following independent variables were considered in the study: mother's age, education, household wealth, residence, employment, media exposure, antenatal care attendance, sex of child, child's age, vaccination status, birth order, baby's size at birth, source of water and toilet facility. Mother's age was defined as 15-24, 25-34 and 35 years and above. Education was categorised as none, primary and secondary or higher. Household wealth was measured as poorest, poorer, middle, richer and richest. Residence was categorised into urban and rural. Employment was grouped into working and not working. Media exposure was defined as exposed and not exposed. Antenatal care attendance was divided into never attended and attended. Sex of child was defined as male and female. Child's age was categorised as $0-11,12-23$ and 24-59 months. Vaccination status was measured as 'No' for children who never had vaccine and 'Yes' for those who were vaccinated. Birth order was expressed as firstorder birth, second-order birth and third or higher order birth. Child's size at birth was defined as large, average and small. Source of water and toilet facility were grouped into improved and not improved.

\section{Statistical analysis}

Data for the 31 countries were pooled together for easy analysis and interpretation. In order to adjust for under-reporting and over-reporting in the surveys, a weighting factor $\left(\frac{v 005}{1000000}\right)$ was applied to the data sets. The suyset command was also used in order to define the data sets as products of survey. The analysis involved both descriptive and multivariable. For the descriptive analysis, $\chi^{2}$ test was used to express relationship between the outcome variables and independent variables. Only the variables that found to be significant from the $\chi^{2}$ test were included in the multivariable analysis. Multivariable analysis involved the application of binary logistic regression model. The model is applied where the outcome variable is dichotomous while the independent variables may 
be of any type. For proper application of the model, each outcome variable was recoded. Children who had fever, cough or diarrhoea were coded as 1 and those who did not suffer from any of the diseases were coded 0 . ORs together with their $95 \%$ CIs were obtained and interpreted. Three $\alpha$ levels $(0.05,0.01$ and 0.001 ) were specified in order to express level of significance. Goodness-of-fit test was conducted in order to ensure that the models were well fitted.

\section{Patient and public involvement}

Patients and the public were not involved in the design and conduct of this research.

\section{RESULTS}

\section{Descriptive statistics}

Table 1 shows that countries with the highest proportions of children suffering from fever include Burundi $(39.0 \%)$, Uganda $(38.8 \%)$ and Liberia $(32.8 \%)$. The countries with the highest proportions of children with cough are Uganda (42.0\%), Burundi (38.3\%) and Cameroon $(38.3 \%)$ while countries with the highest proportions of children suffering from diarrhoea are Liberia (24.8\%), Uganda (22.4\%) and Burundi (21.9\%). Results from table 2 show that in sub-Saharan Africa, about $22 \%$ of children suffered from fever, $23 \%$ suffered from cough and $16 \%$ suffered from diarrhoea. Morbidity is predominant among children of women who are within the age

Table 1 Year of survey, number of children and childhood morbidity in sub-Saharan Africa

\begin{tabular}{|c|c|c|c|c|c|}
\hline \multirow[b]{2}{*}{ Country } & \multirow[b]{2}{*}{ Year of survey } & \multirow[b]{2}{*}{ Children (n) } & \multicolumn{3}{|c|}{ Childhood morbidity } \\
\hline & & & Fever (\%) & Cough (\%) & Diarrhoea (\%) \\
\hline Angola & 2015-2016 & 6765 & 15.9 & 11.1 & 14.4 \\
\hline Benin & $2017-2018$ & 12256 & 19.5 & 16.3 & 10.8 \\
\hline Burkina Faso & 2010 & 6837 & 22.4 & 10.6 & 15.6 \\
\hline Burundi & 2016-2017 & 6069 & 39.0 & 38.3 & 21.9 \\
\hline Cameroon & 2011 & 5286 & 29.0 & 38.3 & 21.5 \\
\hline Chad & 2014-2015 & 10775 & 21.7 & 19.4 & 20.0 \\
\hline Comoros & 2012 & 2886 & 21.5 & 17.8 & 16.3 \\
\hline Congo & 2011-2012 & 4621 & 26.9 & 27.5 & 17.2 \\
\hline Cote d'Ivoire & 2011-2012 & 3488 & 25.3 & 21.2 & 18.7 \\
\hline $\begin{array}{l}\text { Democratic Republic of } \\
\text { Congo }\end{array}$ & 2013-2014 & 8552 & 31.1 & 32.3 & 17.2 \\
\hline Ethiopia & 2016 & 9696 & 13.8 & 16.1 & 11.1 \\
\hline Gabon & 2012 & 3594 & 23.7 & 37.8 & 17.8 \\
\hline Gambia & 2013 & 3640 & 13.2 & 13.5 & 18.3 \\
\hline Ghana & 2014 & 2782 & 15.2 & 14.0 & 12.1 \\
\hline Guinea & 2018 & 3582 & 16.1 & 11.4 & 11.7 \\
\hline Kenya & 2014 & 19344 & 24.2 & 35.8 & 15.0 \\
\hline Lesotho & 2014 & 1381 & 15.1 & 27.7 & 12.2 \\
\hline Liberia & 2013 & 3329 & 32.8 & 29.3 & 24.8 \\
\hline Malawi & 2015-2016 & 5384 & 29.9 & 24.4 & 20.6 \\
\hline Mali & 2018 & 8908 & 16.6 & 9.6 & 17.6 \\
\hline Namibia & 2013 & 1945 & 27.8 & 32.4 & 20.4 \\
\hline Niger & 2012 & 5576 & 13.3 & 14.1 & 14.2 \\
\hline Nigeria & 2018 & 11704 & 25.8 & 17.0 & 12.7 \\
\hline Rwanda & 2014-2015 & 3615 & 18.9 & 28.4 & 12.7 \\
\hline Senegal & 2010-2011 & 4323 & 21.4 & 19.7 & 20.3 \\
\hline South Africa & 2016 & 1460 & 19.9 & 25.9 & 10.8 \\
\hline Tanzania & 2015-2016 & 9213 & 17.8 & 16.3 & 12.1 \\
\hline Togo & 2013-2014 & 3274 & 22.8 & 27.8 & 16.4 \\
\hline Uganda & 2016 & 4530 & 38.8 & 42.0 & 22.4 \\
\hline Zambia & 2018 & 9100 & 16.9 & 21.2 & 15.6 \\
\hline Zimbabwe & 2015 & 5253 & 14.3 & 37.5 & 16.9 \\
\hline
\end{tabular}




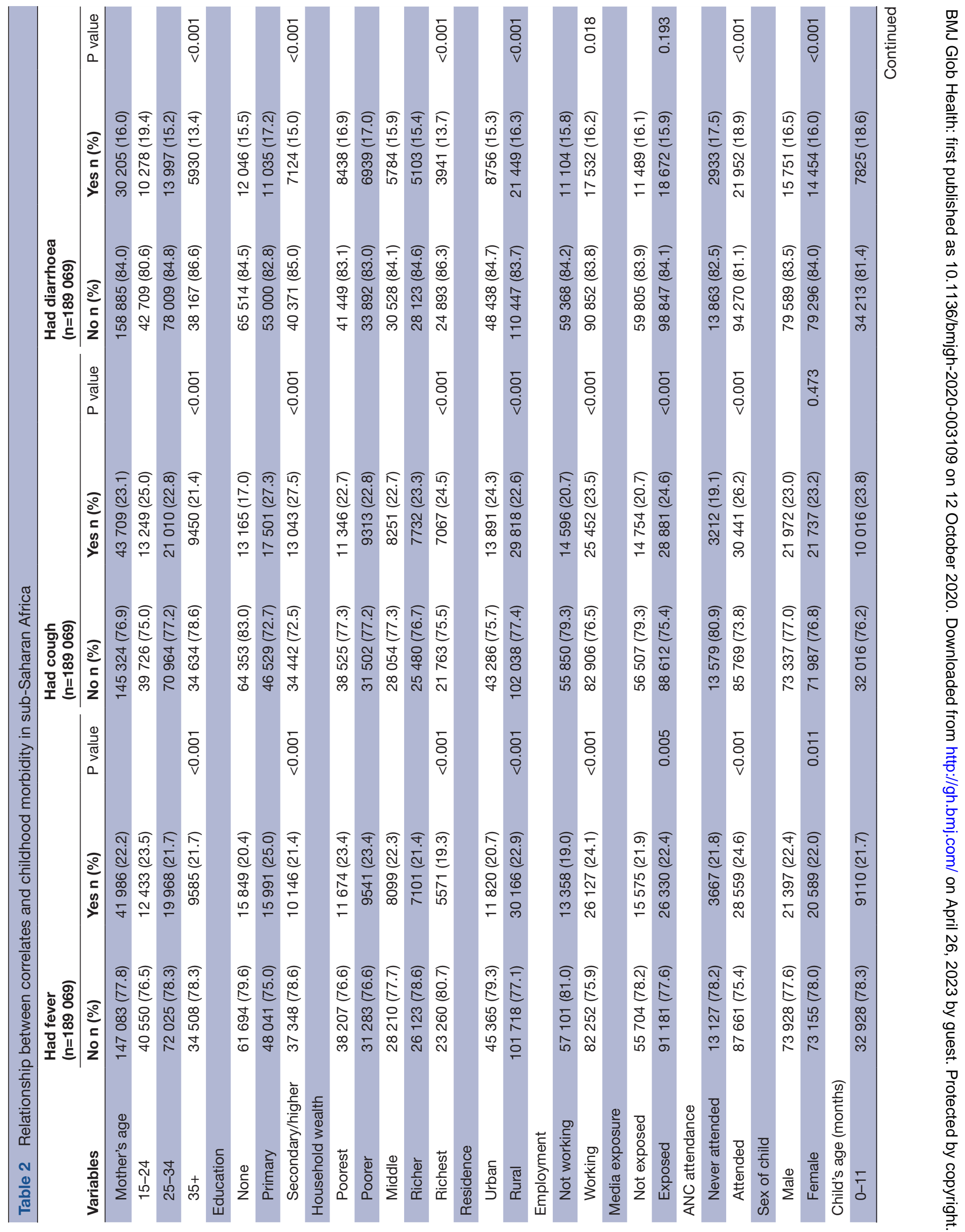




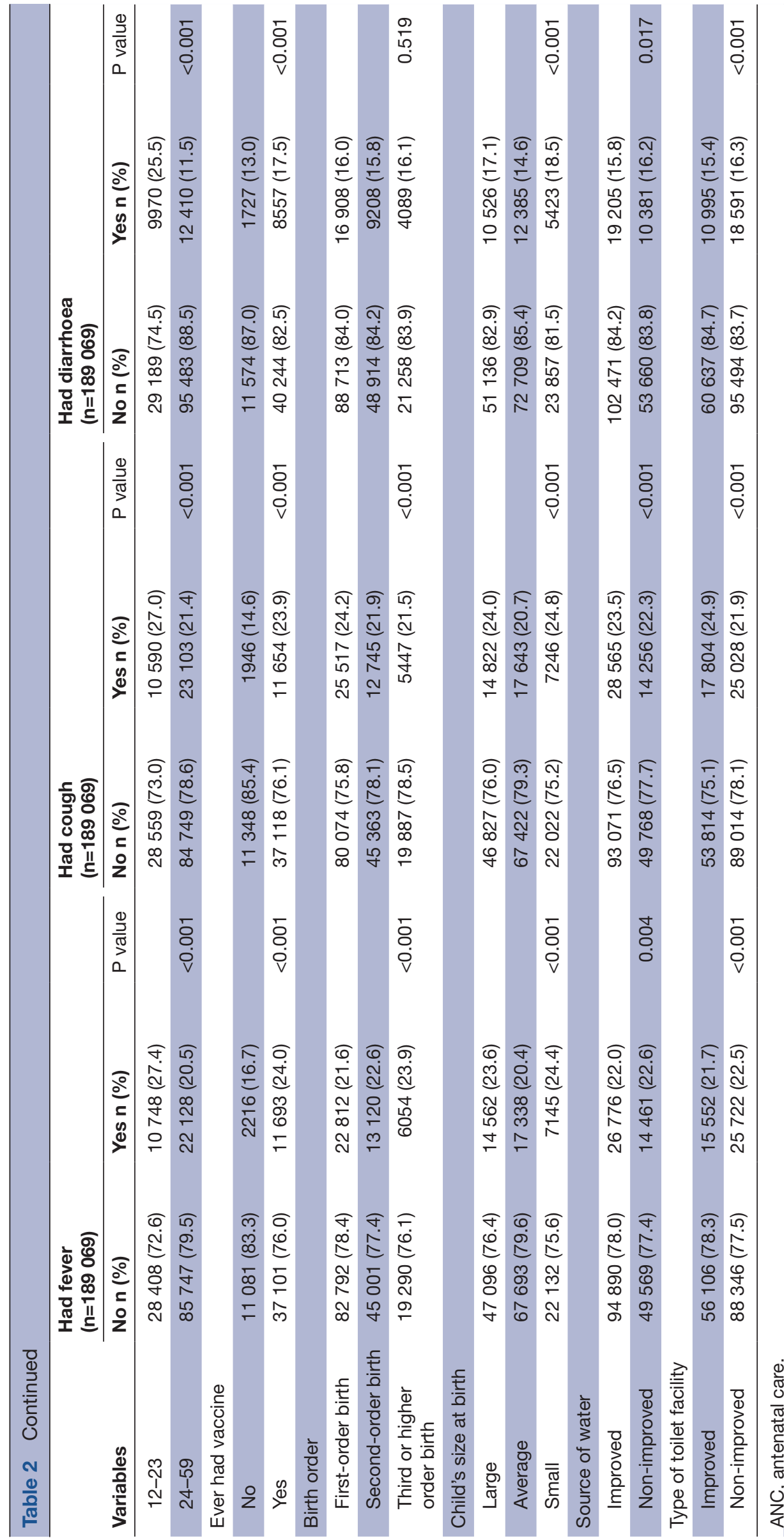


group 15-24. Among this category of women, about $24 \%$ of children suffered from fever, $25 \%$ suffered from cough and $19 \%$ suffered from diarrhoea. Morbidity is very common among children of women who have primary education as one-quarter of the children had fever (25\%), $27 \%$ had cough and $17 \%$ had diarrhoea. With respect to household wealth, morbidity is most prevalent among children from the poorest and poorer households. While $23 \%$ of these children experienced fever and cough, $17 \%$ experienced diarrhoea. Childhood morbidity tends to be higher among children of working women than it is among children of non-working women. About $24 \%$ of children of working women experienced fever and cough while $16 \%$ experienced diarrhoea. A similar scenario is observed in respect of media exposure as $22 \%$ of children of women who are exposed to media had fever and $25 \%$ had cough. With respect to child's age, morbidity is most pronounced among children who are between 12 and 23 months old. More than one-quarter (27\%) of children within this age bracket suffered from fever and cough while $26 \%$ suffered from diarrhoea. Results from child's size at birth indicate that children who were small at birth experienced morbidity most. Among this category of children, $24 \%$ experienced fever, $25 \%$ experienced cough and $19 \%$ experienced diarrhoea.

\section{Multivariable analysis}

Table 3 shows the results of the binary logistic regression which highlights the factors that are associated with childhood morbidity. The goodness-of-fit test results for the three models $(0.853,0,839$ and 0.461$)$ indicate the models were well fitted.

\section{Fever}

Results show that children of women aged 15-24 are 46\% more likely to suffer from fever compared with children of women who are 35 years and older. Children of women aged 25-34 years are 19\% more likely to suffer from fever compared with children of women aged 35 years and older. The odds of experiencing fever is 0.85 for children of women who have no education. The odds of suffering from fever increased by $37 \%$ and $18 \%$, respectively, for children of women from poorest and poorer households. Children of non-working women are $21 \%$ less likely to suffer from fever compared with children of working women. While the odds of experiencing fever reduced by $16 \%$ for children aged $0-11$ months, the odds increased by $13 \%$ for children who are between 12 and 23 months. Children who did not receive immunisation are $32 \%$ less likely to experience fever compared with children who received immunisation. Children of second-order birth and third or higher order birth are $16 \%$ and $33 \%$, respectively, more likely to suffer from fever compared with children of first-order birth. While the odds of suffering from fever reduced by $19 \%$ for children who were of average size at birth, the odds increased by $16 \%$ for children who were small at birth.

\section{Cough}

The odds of experiencing cough increased by $32 \%$ and $19 \%$, respectively, for children whose mothers are in the age brackets of 15-24 and 25-34. Children whose mothers have no education are $35 \%$ less likely to experience cough compared with children whose mothers have secondary or higher education. Children of nonworking women are $15 \%$ less likely to suffer from cough. The odds of suffering from cough reduced by $9 \%$ and $33 \%$, respectively, for children aged $0-11$ months and those who did not receive immunisation. Children of third or higher order birth are $14 \%$ more likely to suffer from cough compared with children of first-order birth. While the odds of suffering from cough reduced by $18 \%$ for children who were of average size at birth, the odds increased by $12 \%$ for children who were small at birth.

\section{Diarrhoea}

Children of women aged 15-24 and 25-34 are 47\% and $23 \%$, respectively, more likely to experience diarrhoea compared with children of women aged 35 years and older. The odds of suffering from diarrhoea increased by $14 \%$ and $26 \%$, respectively, for children whose mothers have no education and those with primary education. The odds of experiencing diarrhoea increased by $28 \%$ and $21 \%$, respectively, for children of women from poorest and poorer households. While children of non-working women are $12 \%$ less likely to experience diarrhoea, female children are $8 \%$ less likely to experience the same disease. The odds of experiencing diarrhoea increased by $15 \%$ and $69 \%$, respectively, for children aged $0-11$ and 12-23 months. Children who did not receive immunisation are $42 \%$ less likely to suffer from diarrhoea compared with children who received immunisation. While the odds of experiencing diarrhoea reduced by $18 \%$ for children who were of average size at birth, the odds increased by $14 \%$ for children who were small at birth. Children who have access to non-improved toilet facility are $15 \%$ more likely to experience diarrhoea compared with children who have access to improved toilet facility.

\section{DISCUSSION}

This study examined the factors associated with childhood morbidity in sub-Saharan Africa. Results revealed that one-fifth of children in sub-Saharan Africa have suffered from fever and cough while $16 \%$ suffered from diarrhoea. Children of women aged 15-24 and 25-34 are more likely to experience morbidity compared with children of women aged 35 years and above. This implies that children of older women have lower tendency of experiencing morbidity compared with children of young and middle-aged women. ${ }^{18-20}$ This may be linked to the notion that older women are more experienced in child care practices than young and middle-aged women. Such experience may have contributed to the knowledge of these women in disease prevention measures. 
Table 3 Logistic regression of correlates of childhood morbidity in sub-Saharan Africa

\section{Childhood morbidity}

\begin{tabular}{|c|c|c|c|}
\hline & Fever & Cough & Diarrhoea \\
\hline Variable & aOR (95\% Cl) & aOR (95\% Cl) & aOR (95\% Cl) \\
\hline \multicolumn{4}{|l|}{ Mother's age } \\
\hline $15-24$ & $1.46^{\star \star \star}(1.29$ to 1.64$)$ & $1.32^{\star \star \star}(1.17$ to 1.48$)$ & $1.47^{\star \star \star}(1.33$ to 1.61$)$ \\
\hline $25-34$ & $1.19^{\star \star *}$ (1.08 to 1.30$)$ & $1.19^{\star * *}$ (1.09 to 1.31$)$ & $1.23^{\star \star \star}(1.12$ to 1.34$)$ \\
\hline $35+$ & 1 & 1 & 1 \\
\hline \multicolumn{4}{|l|}{ Education } \\
\hline None & $0.85^{\star *}(0.77$ to 0.94$)$ & $0.65^{\star \star \star}(0.59$ to 0.72$)$ & $1.14^{\star \star}(1.04$ to 1,26$)$ \\
\hline Primary & 1.04 (0.95 to 1.14$)$ & 0.99 (0.92 to 1.09$)$ & $1.26^{\star \star *}(1.14$ to 1.39$)$ \\
\hline Secondary/higher & 1 & 1 & 1 \\
\hline \multicolumn{4}{|l|}{ Household wealth } \\
\hline Poorest & $1.37^{\star \star \star}(1.19$ to 1.58$)$ & 1.09 (0.93 to 1.27$)$ & $1.28^{* *}(1.11$ to 1.49$)$ \\
\hline Poorer & $1.18^{*}(1.03$ to 1.35$)$ & 1.01 (0.88 to 1.16$)$ & $1.21^{\star \star}(1.05$ to 1.39$)$ \\
\hline Middle & $1.15^{\star}(1.01$ to 1.31$)$ & 0.99 (0.87 to 1.14$)$ & 1.07 (0.93 to 1.24$)$ \\
\hline Richer & 1.109 (0.97 to 1.24$)$ & 1.02 (0.89 to 1.15$)$ & 1.10 (0.96 to 1.27$)$ \\
\hline Richest & 1 & 1 & 1 \\
\hline \multicolumn{4}{|l|}{ Residence } \\
\hline Urban & 1 & 1 & 1 \\
\hline Rural & 1.04 (0.94 to 1.15$)$ & 0.96 (0.86 to 1.07$)$ & 0.94 (0.85 to 1.05$)$ \\
\hline \multicolumn{4}{|l|}{ Employment } \\
\hline Not working & $0.79^{\star \star \star}(0.74$ to 0.86$)$ & $0.85^{\star \star \star}(0.79$ to 0.92$)$ & $0.88^{\star \star *}(0.82$ to 0.94$)$ \\
\hline Working & 1 & 1 & 1 \\
\hline \multicolumn{4}{|l|}{ Media exposure } \\
\hline Not exposed & 0.98 (0.91 to 1.05$)$ & 0.98 (0.91 to 1.05$)$ & \\
\hline Exposed & 1 & 1 & \\
\hline \multicolumn{4}{|l|}{ ANC attendance } \\
\hline Never attended & 1.00 (0.93 to 1.09$)$ & 1.01 (0.92 to 1.10$)$ & 1.05 (0.96 to 1.14$)$ \\
\hline Attended & 1 & 1 & 1 \\
\hline \multicolumn{4}{|l|}{ Sex of child } \\
\hline Male & 1 & & 1 \\
\hline Female & 0.96 (0.89 to 1.02$)$ & & $0.92^{*}(0.86$ to 0.98$)$ \\
\hline \multicolumn{4}{|l|}{ Child's age (months) } \\
\hline $0-11$ & $0.84^{\star \star \star}(0.78$ to 0.91$)$ & $0.91^{*}(0.83$ to 0.99$)$ & $1.15^{\star *}(1.06$ to 1.26$)$ \\
\hline $12-23$ & $1.13^{* \star}(1.05$ to 1.21$)$ & 0.97 (0.90 to 1.05$)$ & $1.69^{\star \star \star}(1.57$ to 1.82$)$ \\
\hline $24-59$ & 1 & 1 & 1 \\
\hline \multicolumn{4}{|l|}{ Ever had vaccine } \\
\hline No & $0.68^{\star \star \star}(0.62$ to 0.74$)$ & $0.67^{\star \star \star}(0.60$ to 0.69$)$ & $0.58^{\star * \star}(0.52$ to 0.64$)$ \\
\hline Yes & 1 & 1 & 1 \\
\hline \multicolumn{4}{|l|}{ Birth order } \\
\hline First-order birth & 1 & 1 & \\
\hline Second-order birth & $1.16^{\star \star}(1.07$ to 1.27$)$ & 1.05 (0.96 to 1.13$)$ & \\
\hline $\begin{array}{l}\text { Third or higher order } \\
\text { birth }\end{array}$ & $1.33^{\star \star \star}(1.19$ to 1.49$)$ & $1.14^{*}(1.01$ to 1.29$)$ & \\
\hline \multicolumn{4}{|l|}{ Child's size at birth } \\
\hline Large & 1 & 1 & 1 \\
\hline Average & $0.81^{* \star *}(0.76$ to 0.87$)$ & $0.82^{* \star \star}(0.77$ to 0.88$)$ & $0.82^{* \star *}(0.76$ to 0.88$)$ \\
\hline
\end{tabular}

Continued 
Table 3 Continued

\begin{tabular}{|c|c|c|c|}
\hline \multirow[b]{3}{*}{ Variable } & \multicolumn{3}{|l|}{ Childhood morbidity } \\
\hline & Fever & Cough & Diarrhoea \\
\hline & aOR $(95 \% \mathrm{Cl})$ & aOR $(95 \% \mathrm{Cl})$ & aOR $(95 \% \mathrm{Cl})$ \\
\hline Small & $1.16^{\star \star}(1.07$ to 1.23$)$ & $1.12^{*}(1.02$ to 1.22$)$ & $1.14^{\star \star}(1.04$ to 1.25$)$ \\
\hline \multicolumn{4}{|l|}{ Source of water } \\
\hline Improved & 1 & 1 & 1 \\
\hline Non-improved & 0.99 (0.93 to 1.07$)$ & 0.97 (0.89 to 1.04$)$ & 0.94 (0.87 to 1.01$)$ \\
\hline \multicolumn{4}{|l|}{ Type of toilet facility } \\
\hline Improved & 1 & 1 & 1 \\
\hline Non-improved & $1.08(0.99$ to 1.17$)$ & $1.09^{*}(1.00$ to 1.18$)$ & $1.15^{\star \star}(1.05$ to 1.25$)$ \\
\hline \multicolumn{4}{|l|}{ Goodness of fit } \\
\hline$F$-adjusted test statistic & 0.531 & 0.550 & 0.972 \\
\hline Prob $>F$ & 0.853 & 0.839 & 0.461 \\
\hline
\end{tabular}

Level of significance at ${ }^{*} \mathrm{p}<0.05 ;{ }^{* \star} \mathrm{p}<0.01 ;{ }^{* * *} \mathrm{p}<0.001$.

ANC, antenatal care; aOR, adjusted OR.

Although results at a point in time indicated that children of uneducated women are less likely to experience fever and cough, other results showed that attaining higher education reduces the chances of experiencing morbidity. ${ }^{21}{ }^{22}$ For instance, children whose mothers are uneducated and those with primary education are more likely to suffer from diarrhoea compared with children whose mothers have secondary or higher education. The possible explanation for these results may be that uneducated women at a point in time observed some measures which prevented their children from experiencing fever and cough but did not take measures to prevent their children from experiencing diarrhoea. Not maintaining personal hygiene and living in an unhygienic environment may contribute to childhood diarrhoea.

Contrarily, this may be an advantage on the part of educated women who place high priority on hygiene. Results also showed that children from poorest and poorer households are more likely to suffer from morbidity than children from richest households. This indicates that there is a significant relationship between household wealth and childhood morbidity. ${ }^{23}{ }^{24}$ Poverty at household level contributes to poor feeding condition of children and forces households to live in poor environment. Poor feeding condition and living in unhygienic environment expose children to morbidity. Children of non-working women are less likely to suffer from any of the diseases compared with children of working women. This has also been reported in other studies. ${ }^{25}$ This may be linked to the fact that non-working women have more time to cater for their children than working women. Working women with young children, especially those in urban areas, tend to put their children under the care of day care providers, housemaids or guardians. In most cases, these children are not properly taken care of which negatively impacts on their health. It is further revealed that children who are within the age bracket of
12-23 months are more likely to suffer from fever and diarrhoea than children who are within the age bracket of 24-59 months. This indicates that younger children are more susceptible to diseases than older children. ${ }^{2627}$ This may be premised on the fact that the older a child becomes, the stronger the immunity he or she builds. However, results showed that unvaccinated children are less likely to suffer from morbidity compared with vaccinated children. This may be linked to the fact that the routine vaccines being administered to children are not meant to prevent any of the diseases under review.

There seems to be a significant relationship between birth order and childhood morbidity as children of second-order birth and third or higher order birth are more likely to experience morbidity than children of firstorder birth. ${ }^{28}$ Ordinarily, one would expect children of higher order birth to suffer less from any of the diseases based on mothers' experience in child care. But previous studies found that mothers tend to allot less attention to children of higher order birth than children of firstorder birth. ${ }^{29}$ This invariably exposes such children to morbidity. The size of child at birth is another important factor influencing childhood morbidity. Children who were small at birth are more likely to experience morbidity than children who were considered large or of average size ${ }^{30}$ This indicates that the smaller a child becomes at birth, the more such child is exposed to morbidity. Environmental factors such as toilet facility also influence childhood morbidity. ${ }^{31-33}$ Children who are exposed to non-improved toilet facility are more likely to suffer from morbidity. Non-improved toilet facility exposes users to germs that are transmitted to utensils in households.

\section{Policy implications}

Efforts at reducing child mortality in sub-Saharan Africa may be jeopardised without a considerable reduction in childhood morbidity. With one-fifth of children suffering 
from fever and cough and 16\% suffering from diarrhoea, childhood morbidity still poses a big challenge to child health in the region. Although it is on record that governments of the countries involved have taken steps at one time or the other to tackle morbidity among children, more measures need to be put in place in order to overcome this challenge. In the first instance, the programmes introduced and sponsored by international organisations in the region with the aim of addressing childhood morbidity should be sustained. It is evident that such programmes have helped in increasing awareness in disease prevention measures among mothers. In addition to this, efforts should be made at national and local levels to strengthen awareness programmes on child health among women.

Since morbidity is more pronounced among children of young and middle-aged women, the focus of such awareness programmes should be on these categories of women. At these programmes, women should be educated on causes of diseases, how children would be prevented from such diseases and, in the event of contracting any disease, what steps to be taken. Apart from this, a community-based forum should be organised on regular basis. At this forum, older women who have accumulated experience in child care should be invited to share their knowledge of child care with younger women. While efforts should be made to establish the factors that contributed to low incidence of fever and cough among children of uneducated women, efforts should be made to increase the percentage of educated women. Education policy that aims at bridging gender gap in enrolment should be promoted. In countries where such policy is already introduced, efforts should be made to ensure effective implementation of such policy. It is obvious that poverty alleviation programmes have been implemented at one time or the other in different countries in subSaharan Africa. Despite this, level of poverty in the region remains high at both individual and household levels. This has eventually contributed to childhood morbidity.

There is a need to review such programmes in order to assess their effectiveness and identify their shortcomings. It is also important to map out other ways by which financial pressure on households, especially in respect of child health, can be reduced. For instance, introduction of child health insurance scheme which offers a comprehensive free healthcare for children right from birth up to age 5. This type of scheme will promote child health and at the same time alleviate household poverty. Based on the findings that children of non-working women are less exposed to the risk of morbidity than children of working women, measures should be taken to ensure adequate child care practices on the part of working women. For instance, those who enrol their children in day care centres should ensure that such centres are located close to their place of work which would afford them the opportunity to check on their children at regular intervals before close of work. At the same time, it would be worthwhile if there is a policy that will mandate employers to make provision for day care facility within their premises. Such facility would enable working mothers to have their children under the care of day care providers within their place of work. Local authority in each country should ensure that toilet facility in each house meets the required standard in order to reduce the proportions of non-improved toilet facility.

\section{Study strengths and weaknesses}

This study shares some of the shortcomings inherent in the use of cross-sectional data sets. Since respondents were interviewed at a point in time, the opportunity to establish a cause-effect relationship between independent and outcome variables is lost. More so, analysis in this study would have been more robust and detailed information would have been provided if there had been variables measuring other childhood diseases. But the data sets were limited to the diseases considered in this study. It should also be noted that the surveys in the 31 countries were not conducted in the same year. There are economic and population disparities in the periods covered by the data sets which this study could not harmonise. In spite of these shortcomings, the study has provided valuable information on the factors that are associated with childhood morbidity in sub-Saharan Africa using the most recent data sets in the countries considered. This has provided this study with an edge over most previous studies on childhood morbidity which limited their findings to specific countries.

\section{CONCLUSIONS}

This study has shown that childhood morbidity in subSaharan Africa is still a major health challenge which needs to be urgently addressed. It is also revealed that factors influencing the phenomenon include mother's age, education, household wealth, employment, child's age, birth order, size of child at birth and toilet facility. Efforts aimed at reducing morbidity among children in the region should incorporate these factors.

\section{Acknowledgements The authors thank the MEASURE DHS project for their support and for free access to the original data.}

Contributors STA and SY conceptualised and designed the study. STA acquired, analysed and interpreted the data. STA and SY drafted and revised the manuscript. SY critically reviewed the manuscript and had the final responsibility to submit for publication. Both authors approved the final manuscript as submitted and agree to be accountable for all aspects of the work.

Funding The authors have not declared a specific grant for this research from any funding agency in the public, commercial or not-for-profit sectors.

Competing interests SY is the associate editor of this journal.

Patient and public involvement Patients and/or the public were not involved in the design, or conduct, or reporting, or dissemination plans of this research.

Patient consent for publication Not required.

Provenance and peer review Not commissioned; externally peer reviewed.

Data availability statement Data are available in a public, open access repository. Data used in this study were obtained from the DHS Program and available at: https://dhsprogram.com/data/available-datasets.cfm.

Open access This is an open access article distributed in accordance with the Creative Commons Attribution Non Commercial (CC BY-NC 4.0) license, which 
permits others to distribute, remix, adapt, build upon this work non-commercially, and license their derivative works on different terms, provided the original work is properly cited, appropriate credit is given, any changes made indicated, and the use is non-commercial. See: http://creativecommons.org/licenses/by-nc/4.0/.

ORCID iD

Sanni Yaya http://orcid.org/0000-0002-4876-6043

\section{REFERENCES}

1 WHO. Children: reducing mortality. Available: https://www.who.int/ news-room/fact-sheets/detail/children-reducing-mortality [Accessed 1 May 2020].

2 UNICEF. Under-five mortality. Available: https://data.unicef.org/topic/ child-survival/under-five-mortality/ [Accessed 2 Jun 2020].

3 UNICEF. Diarrhoeal disease. Available: https://data.unicef.org/topic/ child-health/diarrhoeal-disease/ [Accessed 6 Jun 2020].

4 UNICEF. Malaria. Available: https://data.unicef.org/topic/childhealth/malaria/ [Accessed 6 Jun 2020].

5 WHO. Malaria in children under five. Available: https://www.who.int/ malaria/areas/high risk groups/children/en/ [Accessed 6 Jun 2020].

6 Melese B, Paulos W, Astawesegn FH, et al. Prevalence of diarrheal diseases and associated factors among under-five children in Dale district, Sidama zone, southern Ethiopia: a cross-sectional study. BMC Public Health 2019;19:1235.

7 Getachew A, Guadu T, Tadie A, et al. Diarrhea prevalence and sociodemographic factors among Under-Five children in rural areas of North Gondar zone, Northwest Ethiopia. Int J Pediatr 2018;2018:1-8.

8 Abuzerr S, Nasseri S, Yunesian M, et al. Water, sanitation, and hygiene risk factors of acute diarrhea among children under five years in the Gaza strip. J Water Sanit Hyg Dev 2020;10:111-23.

9 Alebel A, Tesema C, Temesgen B, et al. Prevalence and determinants of diarrhea among under-five children in Ethiopia: a systematic review and meta-analysis. PLoS One 2018;13:e0199684.

10 Mulatya DM, Ochieng C. Disease burden and risk factors of diarrhoea in children under five years: evidence from Kenya's demographic health survey 2014. Int J Infect Dis 2020;93:359-66.

11 GBD 2017 Diarrhoeal Disease Collaborators. Quantifying risks and interventions that have affected the burden of diarrhoea among children younger than 5 years: an analysis of the global burden of disease study 2017. Lancet Infect Dis 2019;20.

12 Afoakwah C, Deng X, Onur I. Malaria infection among children under-five: the use of large-scale interventions in Ghana. BMC Public Health 2018;18:536.

13 Morakinyo OM, Balogun FM, Fagbamigbe AF. Housing type and risk of malaria among under-five children in Nigeria: evidence from the malaria indicator survey. Malar J 2018;17:311.

14 Nyirakanami C, Chibvongodze R, Habtu M, et al. Prevalence and risk factors of asymptomatic malaria among Under-five children in Huye district, southern Rwanda. Tanzan J Health Res 2018;20.

15 Hajison PL, Feresu SA, Mwakikunga BW. Malaria in children underfive: a comparison of risk factors in lakeshore and highland areas, Zomba district, Malawi. PLoS One 2018;13:e0207207.

16 Dagne H, Andualem Z, Dagnew B, et al. Acute respiratory infection and its associated factors among children under-five years attending pediatrics ward at University of Gondar comprehensive specialized Hospital, Northwest Ethiopia: institution-based cross-sectional study. BMC Pediatr 2020;20:93.
17 Alemayehu S, Kidanu K, Kahsay T, et al. Risk factors of acute respiratory infections among under five children attending public hospitals in southern Tigray, Ethiopia, 2016/2017. BMC Pediatr 2019;19:380.

18 Vasconcelos MJdeOB, Rissin A, Figueiroa JN, et al. Factors associated with diarrhea in children under five years old in the state of Pernambuco, according to surveys conducted in 1997 and 2006. Rev Saude Publica 2018;52:48.

19 Gayawan E, Aladeniyi OB, Oladuti OM, et al. Investigating the spatial patterns of common childhood morbidity in six neighboring West African countries. J Epidemiol Glob Health 2019;9:315.

20 Pinzón-Rondón Ángela María, Aguilera-Otalvaro P, ZárateArdila $\mathrm{C}$, et al. Acute respiratory infection in children from developing nations: a multi-level study. Paediatr Int Child Health 2016;36:84-90.

21 Desmennu AT, Oluwasanu MM, John-Akinola YO, et al. Maternal education and diarrhea among children aged 0-24 months in Nigeria. Afr J Reprod Health 2017;21:27-36.

22 Tazinya AA, Halle-Ekane GE, Mbuagbaw LT, et al. Risk factors for acute respiratory infections in children under five years attending the Bamenda Regional Hospital in Cameroon. BMC Pulm Med 2018;18:7.

23 Adesanya OA, Darboe A, Mendez Rojas B, Rojas BM, et al. Factors contributing to regional inequalities in acute respiratory infections symptoms among under-five children in Nigeria: a decomposition analysis. Int J Equity Health 2017;16:140.

24 Nworie KM, Oyine Aluh D, Aluh DO. Determinants of diarrhea and optimal childcare among Under-Five children in Nigeria: insights from the 2013 demographic and health survey. Fam Med Med Sci Res 2018;07.

25 Gashawa TA, Walie YM. Prevalence and determinate factors of diarrhea morbidity among under five children in shake zone, Southwest Ethiopia, a community based cross-sectional study. Arch Community Med Public Health 2019;5.

26 Takele K, Zewotir T, Ndanguza D. Risk factors of morbidity among children under age five in Ethiopia. BMC Public Health 2019;19.

27 Kumi-Kyereme A, Amo-Adjei J. Household wealth, residential status and the incidence of diarrhoea among children under-five years in Ghana. J Epidemiol Glob Health 2016;6:131-40.

28 Akinyemi JO, Morakinyo OM. Household environment and symptoms of childhood acute respiratory tract infections in Nigeria, 2003-2013: a decade of progress and stagnation. BMC Infect Dis 2018;18:296.

29 Adedokun ST. Correlates of childhood morbidity in Nigeria: evidence from ordinal analysis of cross-sectional data. PLoS One 2020;15:e0233259.

30 Choube A, Kumar B, Mahmood S, et al. Potential risk factors contributing to acute respiratory infections in under five age group children. Int J Med Sci Public Health 2014;3:1385.

31 Workie GY, Akalu TY, Baraki AG. Environmental factors affecting childhood diarrheal disease among under-five children in Jamma district, South Wello zone, northeast Ethiopia. BMC Infect Dis 2019;19:804.

32 Ullah MB, Mridha MK, Arnold CD, et al. Factors associated with diarrhea and acute respiratory infection in children under two years of age in rural Bangladesh. BMC Pediatr 2019;19:386.

33 Degebasa MZ, Weldemichael DZ, Marama MT. Diarrheal status and associated factors in under five years old children in relation to implemented and unimplemented community-led total sanitation and hygiene in YaYa Gulele in 2017. Pediatric Health Med Ther 2018;9:109-21. 